\title{
Aspartate $\beta$-hydroxylase as a target for cancer therapy
}

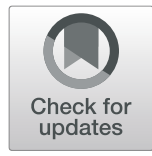

\author{
Madiha Kanwall ${ }^{1}$ Michal Smahel $^{1 *}$ (D), Mark Olsen ${ }^{2,3}$, Jana Smahelova ${ }^{1}$ and Ruth Tachezy ${ }^{1}$
}

\begin{abstract}
As metastasis is a major cause of death in cancer patients, new anti-metastatic strategies are needed to improve cancer therapy outcomes. Numerous pathways have been shown to contribute to migration and invasion of malignant tumors. Aspartate $\beta$-hydroxylase (ASPH) is a key player in the malignant transformation of solid tumors by enhancing cell proliferation, migration, and invasion. ASPH also promotes tumor growth by stimulation of angiogenesis and immunosuppression. These effects are mainly achieved via the activation of Notch and SRC signaling pathways. ASPH expression is upregulated by growth factors and hypoxia in different human tumors and its inactivation may have broad clinical impact. Therefore, small molecule inhibitors of ASPH enzymatic activity have been developed and their anti-metastatic effect confirmed in preclinical mouse models. ASPH can also be targeted by monoclonal antibodies and has also been used as a tumor-associated antigen to induce both cluster of differentiation (CD) $8^{+}$and $C D 4^{+}$T cells in mice. The PAN-301-1 vaccine against ASPH has already been tested in a phase 1 clinical trial in patients with prostate cancer. In summary, ASPH is a promising target for anti-tumor and anti-metastatic therapy based on inactivation of catalytic activity and/or immunotherapy.
\end{abstract}

Keywords: ASPH, Small molecule inhibitor, Metastasis, Immunotherapy

\section{Background}

Cancer is a multifactorial disease with an approximate 9.6 million fatalities in 2018. Worldwide, it is the second leading cause of death [1]. The complex modifications in the genome affected by the interactions between host and environment lead to cancer development and progression. Despite advancements in characterizing the molecular mechanisms of oncogenesis, tumor progression and metastasis [2], delayed cancer detection, limited surgical options, therapeutic resistance, and tumor recurrence are serious obstacles in decreasing the prevalence and fatality rate of cancer. Since metastasis is the primary cause of deaths from cancer, the design of therapeutic approaches that target mechanisms of tumor-cell migration and invasiveness is essential. In this

\footnotetext{
* Correspondence: smahelm@natur.cuni.cz

'Department of Genetics and Microbiology, Faculty of Science, Charles University, BIOCEV, Vestec, Czech Republic

Full list of author information is available at the end of the article
}

regard, a growing number of investigations of signaling pathways involving products of oncogenes and tumor suppressor genes in human carcinomas has helped to elucidate the mechanisms underlying malignant transformation of cells and facilitated the development of new and more efficient therapeutic methods.

Aspartate $\beta$-hydroxylase (ASPH) has been identified as one of the cell surface proteins associated with malignant transformation of tumor cells [3, 4]. ASPH belongs among the most important biological targets to control migration and invasion of tumor cells, as its overexpression has been observed in 70-90\% of human solid tumors [5-7]. The overexpressed ASPH is transported from the endoplasmic reticulum to the plasma membrane which results in exposure of the C-terminal region to the extracellular environment where it is accessible to antibody binding. Recently, molecular targeted therapy has been developed against this target using small molecule inhibitors (SMI) that can inhibit the catalytic site 
in the C-terminal region. Moreover, as antigenic epitopes that reside on the ASPH protein can efficiently stimulate cluster of differentiation (CD) $4^{+}$and $\mathrm{CD}^{+} \mathrm{T}$ cell responses unique to tumor cells harboring ASPH, this enzyme can be used as a tumor associated antigen (TAA) in immunotherapy $[8,9]$.

\section{Structure of the ASPH gene and isoforms}

ASPH is a type II transmembrane protein of approximately $86 \mathrm{kDa}$ that belongs to the family of $\alpha$ ketoglutarate-dependent dioxygenases. The $\beta$ hydroxylated products of ASPH hydroxylation were first detected in blood coagulation proteins [10-18]. ASPH was initially identified in the bovine liver as an enzyme responsible for catalyzing the hydroxylation of aspartyl and asparaginyl residues in calcium binding epidermal growth factor (cbEGF)-like domains of various proteins [19] (Fig. 1). Thereafter, the human ASPH gene was cloned and characterized [20]. This gene spanning 214, 085 base pairs long region of genomic DNA and containing 33 exons is located at the position q12.3 of the human chromosome 8 . The ASPH sequence is highly conserved in mammalian evolution. The sequence of the human protein is from about $85 \%$ identical to the sequences of rat and mouse analogs and the catalytic site is quite conserved among proteins of these three species [7]. The whole ASPH protein consists of five domains: an $\mathrm{N}$-terminal cytoplasmic, a universal transmembrane, a positively charged luminal, a calcium binding, and a Cterminal catalytic domain [21]. Tissue specific transcription is directed from two putative promoters, P1 and P2, which differ in their regulation sequences [21, 22]. While the transcription from the P1 promoter was observed in most human tissues, the $\mathrm{P} 2$ promoter is activated by the calcium-dependent transcription factor myocyte enhancer factor 2 (MEF2), particularly in muscle tissues [21]. The $A S P H$ gene undergoes extensive alternative splicing resulting in four protein isoforms, i.e. ASPH, humbug, junctate, and junctin $[23,24]$. These proteins vary in the C-terminal region, which affects their function [25, 26]. The two longest ASPH transcript variants, that are transcribed from the P1 and P2 promoters and differ in the length of the $5^{\prime}$-untranslated region, encode the fulllength ASPH protein. This protein contains the catalytic C-terminal domain that catalyzes the post-translational hydroxylation in the cbEGF-like domains of numerous proteins (Supplementary Fig. 1), including receptors, receptor ligands, and extracellular adhesion molecules, that influence cell motility and invasiveness $[5,25]$. The truncated isoforms, humbug, junctate, and junctin, share the $\mathrm{N}$-terminal part with the ASPH protein but lack catalytic function. They are involved in calcium homeostasis [27]. Humbug has a potential role in cell adhesion and calcium flux and similar to ASPH, its overexpression has been correlated with aggressive tumor-cell behavior [28]. Junctate is a sarco(endo)plasmic reticulum membrane-bound protein that is known for its function in the regulation of the intracellular $\mathrm{Ca}^{2+}$ concentration. Junctin is a structural membrane protein and as an integral part of the complex consisting of the ryanodine receptor, calsequestrin and triadin influences calcium release from the sarcoplasmic reticulum [24, 27, 29].

\section{Localization in cells, tissue distribution, and expression regulation}

ASPH is predominantly a cell-surface protein [30] that is also localized in the endoplasmic and sarcoplasmic reticulum [31]. Furthermore, a recent study identified mitochondrial localization of ASPH in hepatocellular carcinoma (HCC). In that study, ASPH overexpression correlated with an instability of mitochondrial DNA and mitochondrial dysfunction that may lead to more aggressive pathological outcomes in HCC [32].

ASPH is abundantly expressed in proliferating placental trophoblastic cells $[3,33]$ and in decidua and endometrial glands [33] and has a potential role in placental implantation and fetal growth [34]. On the contrary, the ASPH expression in normal adult tissues is relatively low or negligible. However, ASPH expression is inappropriately activated during oncogenesis when $\mathrm{ASPH}$ is required for generation of malignant and metastatic phenotypes. The elevated expression of ASPH at both

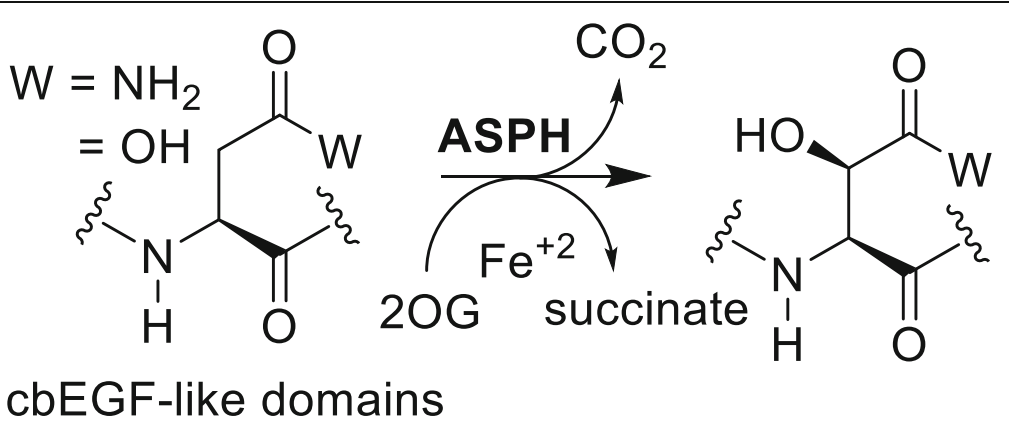

Fig. 1 ASPH catalytic reaction. Aspartyl and asparaginyl residues in cbEGF-like domains are hydroxylated 
transcription and translation levels has been shown in a wide range of transformed cell lines as well as human carcinoma tissues including hepatocellular, pancreatic, colon, prostate, lung, breast, ovarian, and cervical carcinoma, cholangiocarcinoma, neuroblastoma, and gastric cancer (Table 1). The first study that demonstrated the significantly higher expression of both ASPH mRNA and protein in HCC and cholangiocarcinoma, relative to their normal adjacent tissue counterparts, was by Lavaissiere et al. [3]. Subsequently, they verified the role of upregulated ASPH protein production and its enzymatic function in the malignant transformation on biliary epithelium, the NIH-3 T3 cell line, and animal models [4]. The level of ASPH also correlated with cell motility and invasiveness in in vitro experiments [30, 38, 44]. In the study by Maeda et al. [36], the overexpression of the ASPH protein was in accordance with worse clinical and histopathological characteristics of the intrahepatic cholangiocarcinomas and prognosis of patients. Similar findings were obtained in other studies for hepatocellular
[40, 45], non-small cell lung [46], and colon carcinomas [47] and glioblastoma multiforme [6]. Recently, the prognostic significance of 2-oxoglutarate-dependent oxygenase expression was demonstrated by analysis of expression profile datasets of 20,752 tumor samples and 881 non-tumor samples. ASPH has been identified as one of the genes which upregulated expression could serve for risk stratification of patients with 9 cancer types [48]. In glioblastoma, the prognostic significance of ASPH was suggested by profiling of alternative mRNA splicing [49].

ASPH gene expression is upregulated via $\mathrm{Wnt} / \beta$-catenin [50] and insulin/insulin-like growth factor 1 (IGF1)/insulin receptor substrate 1 (IRS1) signaling [25, 37, 38] through extracellular signal-regulated kinase (ERK)/mitogen-activated protein kinase (MAPK) and phosphatidylinositol-3-kinase/protein kinase B (PI3KAkt) pathways (Fig. 2; for review, see ref. [26]). Insulin/ IGF1/IRS1 signaling affects cell growth and survival and can be involved in oncogenesis in various human tumors

Table 1 Summary of the studies, which have identified the elevated ASPH expression in human tumor tissues

\begin{tabular}{|c|c|c|c|c|}
\hline Study & Tumor tissues & Positive cases of studied samples (n/n) & $\begin{array}{l}\text { Detection } \\
\text { method }\end{array}$ & $\begin{array}{l}\text { Antibody (recognized region of } \\
\text { ASPH protein) }\end{array}$ \\
\hline \multirow{4}{*}{$\begin{array}{l}\text { Lavaissiere } \\
\text { et al., [3] }\end{array}$} & Hepatocellular & $4 / 10$ & \multirow[t]{4}{*}{$\mathrm{IHC}$} & \multirow[t]{4}{*}{ FB-50 Ab (N-terminus) } \\
\hline & Cholangiocarcinoma & $20 / 20$ & & \\
\hline & Breast & $4 / 4$ & & \\
\hline & Colon & $6 / 10$ & & \\
\hline $\begin{array}{l}\text { Palumbo } \\
\text { et al., [35] }\end{array}$ & Pancreatic adenocarcinoma & $19 / 19$ & $\mathrm{IHC}$ & FB-50 Ab (N-terminus) \\
\hline $\begin{array}{l}\text { Sepe et al., } \\
\text { [30] }\end{array}$ & $\begin{array}{l}\text { Primitive neuroectodermal } \\
\text { (medulloblastoma, neuroblastoma) }\end{array}$ & $28 / 28$ & $\mathrm{IHC}$ & FB-50 Ab (N-terminus) \\
\hline $\begin{array}{l}\text { Maeda et al., } \\
\text { [36] }\end{array}$ & Cholangiocarcinoma & $42 / 50$ & $\mathrm{IHC}$ & FB-50 Ab (N-terminus) \\
\hline \multirow[t]{2}{*}{$\begin{array}{l}\text { Cantarini } \\
\text { et al., [37] }\end{array}$} & \multirow[t]{2}{*}{ Hepatocellular } & $13 / 15$ & $\mathrm{IHC}$ & \multirow[t]{2}{*}{$\begin{array}{l}\text { FB-50 Ab (N-terminus) or } 15 C 7 \text { Ab } \\
\text { (catalytic domain) }\end{array}$} \\
\hline & & $\begin{array}{l}\text { 13/15 (7.5-fold higher level of mRNA } \\
\text { compared to normal tissue) }\end{array}$ & RT-qPCR & \\
\hline \multirow{2}{*}{$\begin{array}{l}\text { Monte et al., } \\
\text { [38] }\end{array}$} & \multirow[t]{2}{*}{ Hepatocellular } & $8 / 8$ & $\mathrm{IHC}$ & \multirow[t]{2}{*}{ FB-50 Ab (N-terminus) } \\
\hline & & $\begin{array}{l}\text { 8/8 (7-fold higher level of mRNA } \\
\text { compared to normal tissue) }\end{array}$ & RT-qPCR & \\
\hline $\begin{array}{l}\text { Yang et al., } \\
{[39]}\end{array}$ & 19 types of tumor tissues ${ }^{a}$ & $94 / 104$ & $\mathrm{IHC}$ & mAb G3 hybridoma \\
\hline $\begin{array}{l}\text { Wang et al., } \\
\text { [40] }\end{array}$ & Hepatocellular & $150 / 233$ & $\mathrm{IHC}$ & Polyclonal \\
\hline $\begin{array}{l}\text { Dong et al., } \\
\text { [41] }\end{array}$ & Pancreatic cancer & $101 / 104$ & $\mathrm{IHC}$ & \multirow[t]{2}{*}{ FB-50 mAb (N-terminus) } \\
\hline $\begin{array}{l}\text { Tang et al., } \\
{[32]}\end{array}$ & Hepatocellular & $71 / 140$ & RT-qPCR & \\
\hline $\begin{array}{l}\text { Lin et al., } \\
{[42]}\end{array}$ & Breast & $127 / 141$ & $\mathrm{IHC}$ & FB-50 Ab (N-terminus) \\
\hline $\begin{array}{l}\text { Ogawa } \\
\text { et al., [43] }\end{array}$ & Pancreatic ductal adenocarcinoma & $162 / 166$ & $\mathrm{IHC}$ & FB-50 Ab (N-terminus) \\
\hline
\end{tabular}

a Liver, kidney, breast, cervical, ovarian, Fallopian tube, laryngeal, lung, thyroid, pancreatic, thymic, prostate, bladder, esophagus, gastric, gall bladder, colon, and rectum cancer and cholangiocarcinoma 


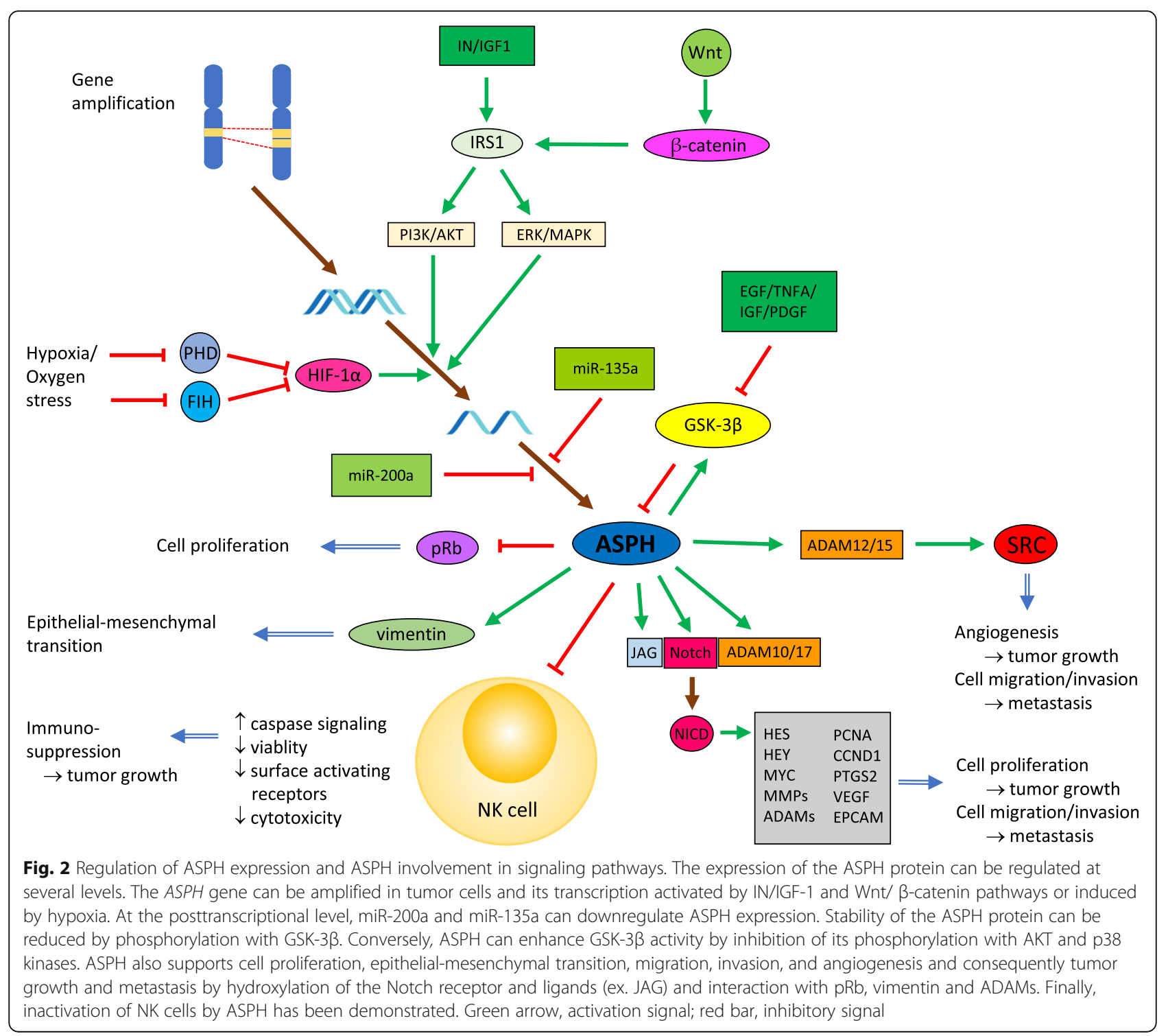

[51]. The $\beta$-catenin-dependent Wnt pathway regulates cell proliferation, motility, and differentiation and is one of the most frequently modified pathways in human malignancies. Upon aberrant activation of Wnt signaling, $\beta$-catenin is accumulated in the cytoplasm and subsequently translocated to the nucleus [52], where an interaction between $\beta$-catenin and T-cell factor/lymphoid enhancer-binding factor (TCF/LEF) proteins forms a transcriptional regulatory complex which enhances the expression of Wnt target genes including IRS1 [53]. ASPH was proposed as a common link between Wnt/ $\beta$ catenin and insulin/IGF1/IRS1 pathways and downstream signaling [54].

The regulation of $A S P H$ gene expression in tumors might also be affected by a copy number variation. In the study by Kadota et al. [55], the $A S P H$ gene locus has been identified as one of the DNA regions with focal amplification in primary breast cancer. In colorectal cancer, $A S P H$ gain or amplification was found in $56 \%$ of samples [56]. Next, a suppressant role of the microRNA miR-200a in posttranscription regulation of the $A S P H$ expression in hepatoma cells has been found [57]. MiR200a belongs to miR-200 family, which plays significant role in preventing cancer initiation and metastasis (for review, see ref. [58]). Similarly, miR-135a has been shown to suppress ASPH in endometrial cancer [59].

Moreover, consistent with the protein sequence analysis that recognized numerous prospective phosphorylation sites of glycogen synthase kinase-3 $\beta$ (GSK-3 $\beta$ ), casein kinase 2 (CK2), protein kinase A (PKA), and protein kinase C (PKC) on ASPH [60], several studies demonstrated that phosphorylation can regulate the ASPH protein expression $[25,52-55]$. Inhibition of the GSK-3 $\beta$ activity did not modify mRNA expression but increased 
the ASPH protein level [25]. Direct phosphorylation of ASPH by GSK- $3 \beta$ probably decreases ASPH stability and thus reduces cell mobility [60]. ASPH protein expression was also increased by inhibitors of PKA, PKC, and CK2 [61]. Mutational analysis of potential sites of phosphorylation demonstrated complex and nonuniform effects of ASPH phosphorylation on protein expression, enzymatic activity, and subcellular localization [62,63]. Therefore, ASPH phosphorylation probably regulates the function of this protein by various mechanisms.

ASPH expression can also be regulated by hypoxia and oxidative stress. In human neuronal cells, this effect was mediated by hypoxia inducible factor 1 alpha (HIF-1 $\alpha$ ) that is stabilized under hypoxia/oxidative stress when the prolyl hydroxylase domain (PHD) proteins and factor inhibiting HIF (FIH) are inactivated. Consequently, the HIF-1 heterodimer made up of subunits HIF- $1 \alpha$ and HIF-1 $\beta$ functions as a transcription factor likely enhancing $A S P H$ expression by binding to hypoxia-responsive elements [64]. In hypoxic regions of glioblastoma, both HIF- $1 \alpha$ and ASPH were highly expressed, particularly in more aggressive mesenchymal subtype of glioblastoma, suggesting a possible involvement of ASPH in mesenchymal transition [6]. Brewitz et al. showed reduced ASPH hydroxylation activity at low oxygen concentrations and suggested an ASPH role in oxygen (hypoxia) sensing. ASPH upregulation induced by hypoxia could compensate for reduced enzymatic activity [65]. Moreover, a recent study reported an oxidative stress state of the castration-resistant prostate cancer cells upon ASPH overexpression which was reversed by silencing $A S P H$ expression or generating hypoxic conditions resulting in impaired cell proliferation and invasion [66].

\section{ASPH protein interactions and signaling pathways}

The ASPH hydroxylation consensus sequence is confined within cbEGF-like domains that are found in proteins of diverse function, including Notch receptors and ligands, clotting factors, structural proteins of the extracellular matrix, and ligands of the tyro-3/Axl family of receptor tyrosine kinases [23].

The Notch signaling cascade is a remarkably conserved pathway. Notch proteins (Notch1 - Notch4) are single-pass cell surface receptors that mediate communication between cells and their expression is crucial for proper embryonic development [67]. Notch signaling mainly results in cell differentiation but also plays a significant role in proliferation, apoptosis, and the maintenance and self-renewal of stem cells. Dysregulation of the Notch pathway is directly linked to cancer, vascular disorders, and congenital defects [68, 69]. In mammals, Notch signaling activated by binding of one of two families of canonical Notch ligands, jagged (JAG1 and JAG2) and delta like (DLL1, DLL3, and DLL4), leads to the generation of the cleaved Notch intracellular domain (NICD) fragment and its nuclear translocation. In the nucleus, the NICD fragment interacts with the DNA binding complex CSL (CBF-1/RBP-jk, Su(H), Lag-1). This complex is then converted from a repressor into an activator leading to increased transcription of target genes such as hes family bHLH transcription factor 1 (HES1), HES with YRPW motif 1 (HEY1), CD44, epithelial cell adhesion molecule (EPCAM), $c-m y c$ proto-oncogene, matrix metallopeptidase 2/9 (MMP2/9), cyclin D1, cyclooxygenase 2, vascular endothelial growth factor (VEGF), and proliferating cell nuclear antigen (PCNA) [26, 41].

Upregulation of ASPH results in enzymatic modification of the cbEGF-like repeats in the Notch receptor extracellular domain and its ligands which promotes the receptor interaction with the ligands and the activation of Notch signaling [37, 41]. Furthermore, the interaction of ASPH with a disintegrin and metallopeptidase domain (ADAM) 10/17 stabilizes this complex and enhances the S2 cleavage of the Notch receptors and subsequent NICD fragment release [42]. The activation of the target genes in malignant cells increases cell proliferation, migration, and invasion [41] through the epithelial-tomesenchymal transition (EMT) that is probably upregulated by the interaction of ASPH with vimentin [70] Consequently, this activation supports tumor growth and metastasis. The ASPH-Notch axis also stimulates the release of exosomes that transfer proteins involved in invasion, metastasis, metabolism, and immunosuppression [42, 71].

The SRC kinase pathway is another important pathway in malignant cell transformation that regulates a complex signaling network promoting angiogenesis, invadopodia formation and maturation, and metastasis [72]. ASPH has been identified as an SRC pathway activator. Overexpressed ASPH directly interacts with ADAM12/ 15 and strengthens the SRC activation by these proteins which promotes MMP-mediated extracellular matrix degradation and tumor invasiveness [43].

ASPH can also contribute to malignant phenotype of cells by interaction with other proteins. Iwagami et al. revealed the interaction of ASPH with GSK-3 $\beta$ that prevents GSK-3 $\beta$ inactivation by phosphorylation with upstream kinases [73]. This mechanism was confirmed in a castration-resistant prostate cancer model [66]. GSK$3 \beta$ is a multifunctional kinase that is involved in various processes including glycogen metabolism, cell division, and cell fate determination. Some types of tumors are sensitive to GSK-3 $\beta$ inhibitors [74]. Recently, Huang et al. elucidated a direct binding of ASPH with retinoblastoma protein $(\mathrm{pRb})$ leading to $\mathrm{pRb}$ phosphorylation [75]. They also showed that this effect was mediated by increased binding of cyclin-dependent kinase (CDK) 2, CDK4, and cyclins D1 and $\mathrm{E}$ with $\mathrm{pRb}$ and was dependent on ASPH enzymatic activity. As 
phosphorylation of $\mathrm{pRb}$ inactivates its tumor-suppressor function, ASPH can contribute to the progression of cell cycle via interaction with $\mathrm{pRb}$.

\section{Effect of ASPH on an immune system}

Tumor generation and progression are influenced by cancer immunoediting that involves immunosurveillance and escape from a host immune system [76]. In these processes, various mechanisms of both innate and adaptive immunity are included [77]. Immune cells that infiltrate developing tumors are initially anti-tumorigenic but in tumor microenvironment, they can be modified into cells with pro-tumorigenic properties [78].

As potential targets of ASPH hydroxylation are also expressed on immune cells, this enzyme could affect the function of immune system, particularly in tumor microenvironment when ASPH is overexpressed on cancer cells. Indeed, such effect was demonstrated for human natural killer (NK) cells by using recombinant ASPH which reduced viability and cytotoxicity of these cells via enhancing caspase signaling and decreasing the surface expression of activating receptors, respectively [79]. Antibodies against ASPH inhibited these effects.

Interaction of ASPH with other immune cells has not been studied. However, we suppose possible influence of ASPH on different tumor-infiltrating cells. This assumption comes from the involvement of Notch signaling in differentiation and function of various immune cells, fibroblasts, mesenchymal cells, and endothelial cells. For instance, Notch activation contributed to stimulation of pro-inflammatory/anti-tumorigenic M1 polarization in both bone marrow-derived primary macrophages $[80$, 81] and tumor-associated macrophages [82]. When Notch signaling was abrogated, pro-tumorigenic M2 polarization was induced even by stimulators of M1 polarization [81]. miR-125a has been identified as a downstream mediator of Notch signaling in macrophages [82]. Similarly, the Notch pathway plays an important role in differentiation of other types of myeloid cells and probably all subsets of $\mathrm{CD}^{+}$and $\mathrm{CD}^{+} \mathrm{T}$ cells [83]. Different Notch receptors and their interaction with different ligands contribute to these processes [84]. Moreover, non-canonical Notch signaling is implicated in regulation of immune cells [85]. While activation of Notch signaling in some cells (e.g. T helper 1 cells, cytotoxic $\mathrm{CD}^{+} \mathrm{T}$ cells, and M1 macrophages) supports induction of immune reactions including anti-tumor immunity, in other cells (particularly regulatory $\mathrm{T}$ cells) it leads to immunosuppression [86]. Thus, immunostimulatory effect of Notch signaling is often inhibited in tumor microenvironment to enable the tumor cells to escape from the host immunity [84]. Therapeutics affecting Notch signaling in malignant diseases are being developed and tested in clinical trials but their effects on immune reactions and possible combination with immunotherapy have not been properly studied.

\section{ASPH as a therapeutic target}

Oncogenic abilities of ASPH have been experimentally demonstrated using tumor cell lines and mouse and rat models of different types of human tumors with ASPH overexpression, including cholangiocarcinoma [4, 44, 75, 87, 88], hepatocellular carcinoma [5, 37, 38, 57, 62, 70, 73], neuroblastoma [30], pancreatic cancer [7, 41, 43, 71], glioma [6], breast carcinoma [42], castration-resistant prostate cancer [66], and colorectal cancer [56]. In studies analyzing ASPH function, various approaches were utilized to reveal signaling pathways affected by ASPH. Particularly, ASPH expression was diminished by using small interfering RNAs $[32,34,38,56,64]$, short hairpin RNAs $[6,73,87]$ or the CRISPR/Cas9 system [42, 56, 73]. The importance of ASPH enzymatic activity in these processes was shown by the site directed mutagenesis $[4,62,63]$ or treatment by SMIs $[5$, $41,42,56,71,87]$. In vitro assays showed ASPH involvement in cell proliferation, migration, and invasion. Cellular alterations included EMT, inhibition of apoptosis, and stemness acquisition. Tumor growth and invasiveness could further be supported by ASPH-induced extracellular matrix degradation, angiogenesis, and transendothelial migration. Notch and SRC signaling are probably major pathways influenced by ASPH (Fig. 2) and contributing to increased aggressiveness of tumor cells that was verified in in vivo models. Thus, these studies also demonstrated that ASPH is a suitable target for cancer treatment, especially by SMIs or immunotherapy.

\section{Small molecule inhibitors}

SMIs of ASPH (Fig. 3) have been developed and used to test the role of ASPH in a wide range of cancer models, including subcutaneous, orthotopic, and patient derived xenograft in vivo models [5, 42, 43, 87]. A small, orally bioavailable inhibitor has several intrinsic advantages over immunotherapy approaches. Not only can these inhibitors inhibit the catalytic activity of ASPH unlike conventional antibodies that simply bind to the protein, but they can also penetrate into the cell and inhibit ASPH catalytic activity in the endoplasmic reticulum. Different cancers have different ASPH expression patterns, and while surface expression is quite common in pancreatic cancer and hepatocellular carcinoma, intracellular overexpression patterns have also been observed [75].

The first ASPH SMIs published were the tetronimides MO-I-500 and MO-I-1100. Tetronimides were originally synthesized in 1953 by Dahn [89], and are redox-active mimics of ascorbic acid and 2-oxoglutarate. MO-I-500 is a mixed inhibitor that inhibits both ASPH and the Fat Mass and Obesity protein (FTO) [90], and is not only orally bioavailable, but also can penetrate the blood- 


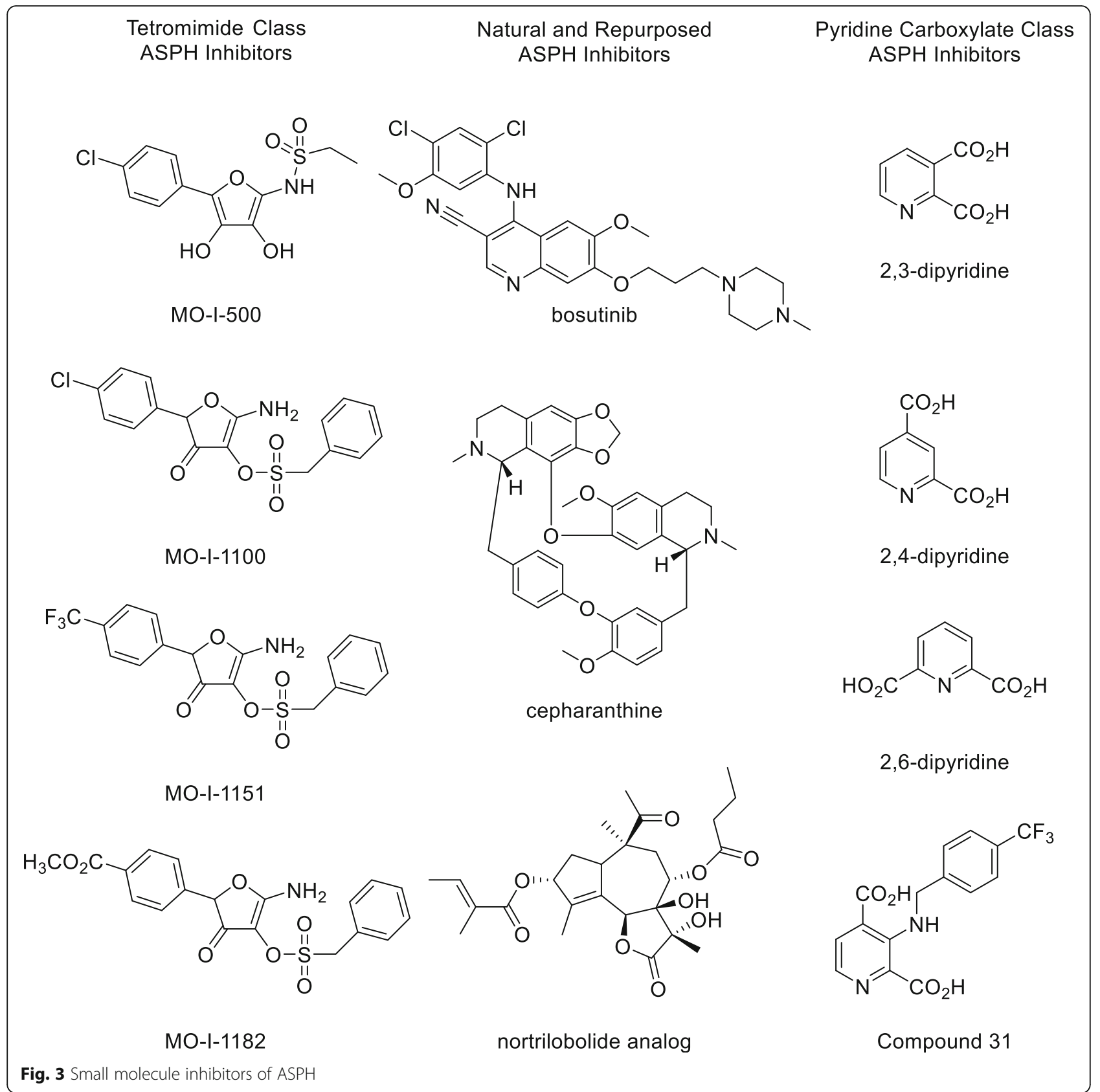

brain barrier. MO-I-1100 is a more potent inhibitor of ASPH and is also more selective [5]. Despite investigation against a wide range of iron-dependent dioxygenases and kinases, there are no other known enzymatic targets for MO-I-1100. Enhanced activity was observed by replacing the chlorine with a trifluoromethyl group [87] as in MO-I-1151 and even a greater improvement in in vivo activity was found by replacing the trifluoromethyl group with a carboxymethyl group as in MO-I-1182, although it is not yet clear if the nature of this enhancement is due to increased inhibitory activity or enhanced solubility parameters. MO-I-1182 is reported to have the ability to suppress invasive activity at a concentration of $50 \mathrm{nM}$ [43]. SMIs of ASPH have a characteristic in vitro concentration dependent profile, where the activity of the SMI plateaus at value around $50 \%$ viability [5], emphasizing the non-cytotoxic properties of this class of inhibitors.

Natural products, and inhibitors of other enzymes that have been repurposed as ASPH inhibitors have also recently been reported in the patent literature, including bosutinib (CN201910141421.9), cepharanthine (CN201910141432.7), and guaianolides related to nortrilobolide (CN201910141418.7; $\quad$ CN201910457588.6). 
Bosutinib is a well-known inhibitor of BCR-ABL and SRC tyrosine kinases approved for the treatment of chronic myelogenous leukemia [91]. Cepharanthine is a natural product sesquiterpene with complex anticancer activity, including AMP-activated protein kinase (AMPK) activation and nuclear factor kappa B (NFkB) inhibition [92]. Nortrilobolide and related compounds are reported to be potent cytotoxic agents with subnanomolar sarco/endoplasmic reticulum calcium ATPase (SERCA) inhibition [93]. Recently, a family of potent pyridine dicarboxylates have also been published [65] utilizing a mass spectrometry-based inhibition assay [94]. These compounds are related to known iron-dependent dioxygenase inhibitors 2,3-pyridine dicarboxylate, 2,4-pyridine dicarboxylate and 2.6-pyridine dicarboxylate. The synthesized pyridine dicarboxylates were assayed for activity against a range of other enzymes, to include PHD2, FIH, and lysine-specific demethylase 4E (KDM4E) in addition to ASPH, with varying degrees of selectivity. However, while cell-based activities have not been evaluated, the dicarboxylate nature of the compounds may be useful for cell surface ASPH inhibitors that may not have cell penetrating activity [94].

\section{Immunotherapy}

ASPH can be used not only as a target of the inhibitors inactivating its enzymatic activity but also as a target of immune reactions leading to destruction of tumor cells and tumor growth suppression. Since ASPH is cell surface displayed on tumor cells, it represents a tumor-associated antigen that can be targeted by both cell-mediated and humoral immunity. As a target of humoral immunity, ASPH on the surface of cancer cells can be bound by antibodies that mediate antibody-dependent cellular cytotoxicity (ADCC), complement dependent cytotoxicity (CDC), or antibody-dependent cellular phagocytosis (ADCP) [95]. When the ASPH antigen is processed in tumor cells or antigen presenting cells, antigenic peptides are presented on these cells by human leukocyte antigen (HLA) class I or class II molecules and recognized by $\mathrm{CD} 8^{+}$or $\mathrm{CD} 4^{+} \mathrm{T}$ lymphocytes, respectively [96], that can be stimulated by immunization breaking tolerance to self-antigens [97].

Induction of ASPH-specific $\mathrm{CD}_{4}^{+}$and $\mathrm{CD} 8^{+} \mathrm{T}$ cells was examined in blood samples of HCC patients. Using synthetic peptides derived from ASPH after prediction of HLA class I- and HLA class II-restricted epitopes, it has been found that ASPH is a highly immunogenic protein that activates both types of analyzed $\mathrm{T}$ cells [9]. Thus, efficient anti-tumor reactions could be stimulated by immunization.

The first vaccine against ASPH was based on matured dendritic cells (DC) loaded with the ASPH protein and tested in an orthotopic rat model of intrahepatic cholangiocarcinoma [98]. This study showed that vaccination stimulated cytotoxicity against cancer cells in an in vitro assay and decreased tumor growth and metastasis. Both
$\mathrm{CD}^{+}$and $\mathrm{CD} 4^{+}$cells contributed to an anti-tumor effect induced in a mouse model of HCC by immunization with ASPH-loaded DCs [8].

The next anti-ASPH vaccine was based on a bacteriophage lambda display system. The viral capsid protein gpD was fused with the $\mathrm{N}$ - or C-terminus of ASPH and immunogenicity of these nanoparticle-forming constructs was verified in two mouse tumor models [99]. The vaccine PAN-301-1 containing these constructs has already been examined in a phase 1 clinical trial in 12 patients with biochemically relapsed prostate cancer [100]. This study demonstrated safety and immunogenicity of PAN-301-1 and indicated an anti-tumor effect in terms of the reduction of prostate specific antigen (PSA) or PSA doubling time. ASPH-specific immune responses were mediated by both antibodies and T lymphocytes.

As ASPH is a type II transmembrane protein, its Cterminus carrying the enzymatic domain is exposed outside cells and can be bound by antibodies that can be used for diagnostic and therapeutic purposes. Development of ASPH-specific antibodies has been described in several articles [101-105]. The human IgG1 PAN-622 recognizes the catalytic domain of ASPH. This antibody is not directly cytotoxic for tumor cells but is internalized and can deliver cytotoxic moieties into cells [84]. In the subsequent study with a mouse model of metastatic breast cancer, PAN-622 was used for bioimaging and radioimmunotherapy with promising results [104]. Mouse IgG1 monoclonal antibody binding to the C-terminal ASPH domain mediated ADCC by human NK cells [103].

Recently, a second-generation antibody approach has been disclosed. The prepared antibody binds to the extreme C-terminus of ASPH (US 20190382506) that is involved in specific substrate recognition [106]. Therefore, this antibody has direct ASPH inhibitory activity and does not require any radioisotope or cytotoxic payload for potential therapeutic activity.

\section{Conclusions}

ASPH is an important enzyme in malignant transformation of cells. It stimulates tumor cell proliferation, migration and invasion but it can also affect other cells in tumor microenvironment. Two main pathways, Notch and SRC, through which ASPH promotes the tumor growth have been identified. It has also been shown that ASPH expression is induced by some growth factors and hypoxia and is regulated at various levels. The overexpression of ASPH and its downstream targets has been detected in numerous human malignancies. Since ASPH is not expressed in appreciable level in normal adult tissues and the catalytic domain is localized on the cell surface, it has been proposed as one of the most exciting potential therapeutic targets (Fig. 4). Small inhibitory molecules, orally bioavailable, have been developed and successfully tested in several cancer 


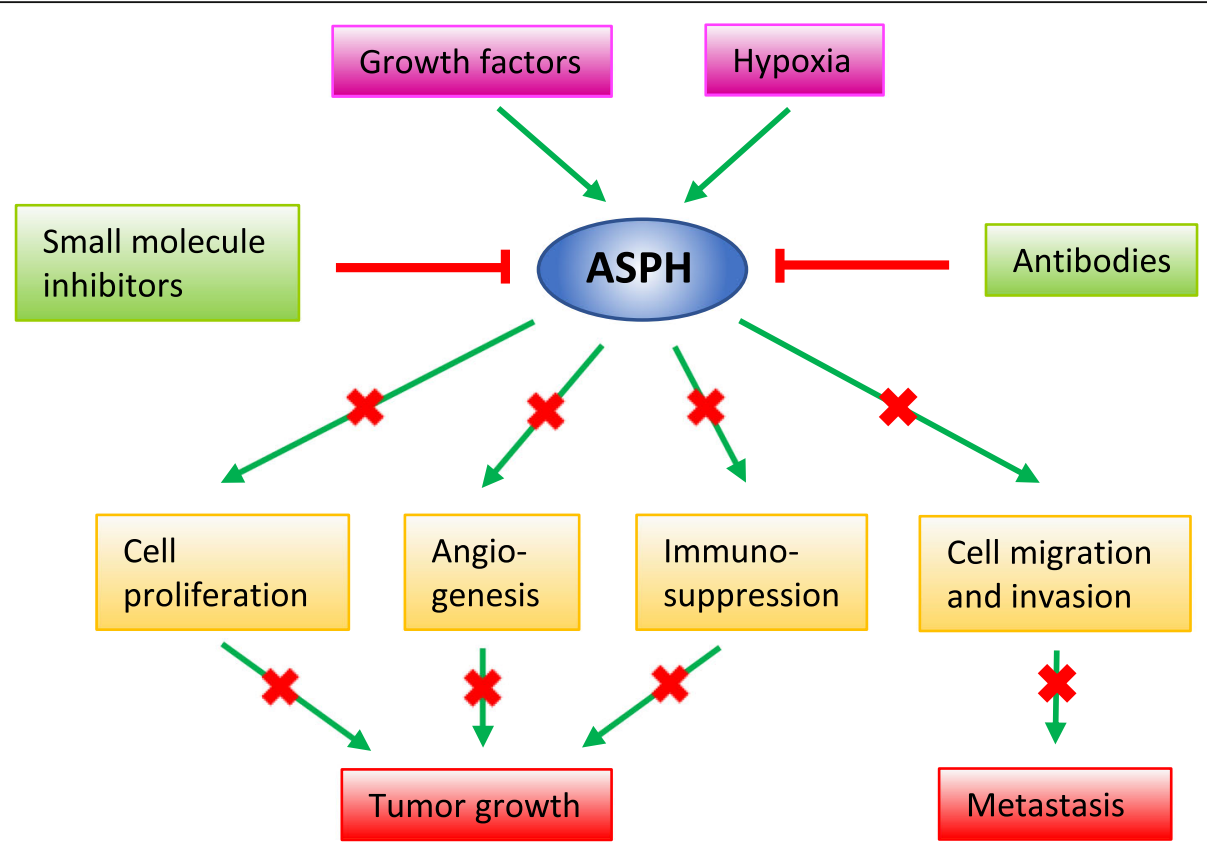

Fig. $4 \mathrm{ASPH}$ as a therapeutic target. ASPH expression is upregulated by growth factors and hypoxia. Its enzymatic activity can be inhibited by SMls or monoclonal antibodies which results in reduction of cell proliferation, angiogenesis, immunosuppression, and cell migration and invasion. Consequently, tumor growth and metastasis are also reduced

models but they have not yet advanced into clinical trials. Additionally, as ASPH was identified as a tumor-associated antigen, immunotherapy approaches, vaccines and monoclonal antibodies, were tested with promising results in preclinical experiments and results of phase I clinical trial with the PAN-301-1 vaccine were published [100].

Despite the progress in understanding ASPH involvement in signaling pathways, the high number of other potential targets of ASPH hydroxylation suggests that the ASPH impact on tumor biology might be more complex, including potential impact on the transforming growth factor beta (TGF- $\beta$ ), growth arrest specific 6/ AXL receptor tyrosine kinase (Gas6/Axl), and Wnt pathways. Even a potential effect of ASPH and its inhibitors on immune cells through the well identified ASPH target, Notch signaling, has not been sufficiently investigated, yet, and should be examined in future studies.

\section{Supplementary information}

Supplementary information accompanies this paper at https://doi.org/10. 1186/s13046-020-01669-w.

\section{Additional file 1: Figure S1.}

Experimental and computationally predicted ASPH substrates.

\section{Abbreviations}

2OG: 2-oxoglutarate; ADAM: A disintegrin and metallopeptidase domain; ADCC: Antibody-dependent cellular cytotoxicity; ADCP: Antibody-dependent cellular phagocytosis; AMPK: AMP-activated protein kinase; ASPH: Aspartate $\beta$-hydroxylase; AXL: AXL receptor tyrosine kinase; cbEGF: Calcium-binding epidermal growth factor; CCND1: Cyclin D1; CD: Cluster of differentiation;
CDC: Complement dependent cytotoxicity; CDK: Cyclin-dependent kinase; CK2: Casein kinase 2; DLL: Delta like; CSL: CBF-1/RBP-jk, Su(H), Lag-1; EGF: Epidermal growth factor; EMT: Epithelial-to-mesenchymal transition; EPCAM: Epithelial cell adhesion molecule; ERK: Extracellular signal-regulated kinase; FIH: Factor inhibiting HIF; FTO: Fat mass and obesity protein; GAS6: Growth arrest specific 6; GSK-3 $\beta$ : Glycogen synthase kinase-3 $\beta$; HCC: Hepatocellular carcinoma; HLA: Human leukocyte antigen; HES1: Hes family bHLH transcription factor 1; HEY1: HES with YRPW motif 1 ; HIF1a: Hypoxia inducible factor 1 alpha; IGF: Insulin-like growth factor; IHC: Immunohistochemistry; IN: Insulin; IRS1: Insulin receptor substrate 1; JAG: Jagged; KDM4E: Lysine-specific demethylase 4E; MAPK: Mitogenactivated protein kinase; MEF2: Myocyte enhancer factor 2;

MMP: Metallopeptidase; MYC: MYC proto-oncogene; NICD: Notch intracellular domain; NFkB: Nuclear factor kappa B; NK: Natural killer; PCNA: Proliferating cell nuclear antigen; PDGF: Platelet derived growth factor; PHD: Prolyl hydroxylase domain; PI3K/Akt: Phosphatidylinositol-3-kinase/protein kinase B; PKA: Protein kinase A; PKC: Protein kinase C; pRB: Retinoblastoma protein; PTGS2: Prostaglandin-endoperoxide synthase 2 (cyclooxygenase 2); RTQPCR: Reverse transcription quantitative polymerase chain reaction; SERCA: Sarco/endoplasmic reticulum calcium ATPase; SRC: SRC tyrosine kinase; SMI: Small molecule inhibitor; TAA: Tumor associated antigen; TCF/ LEF: T-cell factor/lymphoid enhancer-binding factor; TGF- $\beta$ : Transforming growth factor beta; TNFA: Tumor necrosis factor alpha; VEGF: Vascular endothelial growth factor

\section{Acknowledgments}

Not applicable.

\section{Authors' contributions}

MK, MS, MO, JS, and RT wrote the manuscript. MS and MO prepared the figures. All authors read and approved the final manuscript.

\section{Funding}

This work was supported by the European Regional Development Fund (the Operational Programme Research, Development and Education), grant number CZ.02.1.01/0.0/0.0/16_019/0000785 and the Ministry of Education, Youth and Sports of the Czech Republic, grant numbers LTAUSA18003 (the program InterExcellence) and LQ1604 (the National Sustainability Program II). 


\section{Availability of data and materials}

Not applicable.

\section{Ethics approval and consent to participate \\ Not applicable.}

\section{Consent for publication}

Not applicable.

\section{Competing interests}

$\mathrm{MO}$ is the CEO of Crenae Therapeutics which has licensed ASPH inhibitor technologies from Midwestern University. The other authors declare that they have no competing interests.

\section{Author details}

'Department of Genetics and Microbiology, Faculty of Science, Charles University, BIOCEV, Vestec, Czech Republic. ${ }^{2}$ Department of Pharmaceutical Sciences, College of Pharmacy - Glendale, Midwestern University, Glendale, AZ, USA. ${ }^{3}$ Crenae Therapeutics, Phoenix, AZ, USA.

Received: 1 July 2020 Accepted: 6 August 2020 Published online: 18 August 2020

\section{References}

1. Bray F, Ferlay J, Soerjomataram I, Siegel RL, Torre LA, Jemal A. Global cancer statistics 2018: GLOBOCAN estimates of incidence and mortality worldwide for 36 cancers in 185 countries. CA Cancer J Clin. 2018;68:394-424.

2. Coyle KM, Boudreau JE, Marcato P. Genetic mutations and epigenetic modifications: driving cancer and informing precision medicine. Biomed Res Int. 2017:2017:9620870.

3. Lavaissiere L, Jia S, Nishiyama M, de la Monte S, Stern AM, Wands JR, et al. Overexpression of human aspartyl(asparaginyl)beta-hydroxylase in hepatocellular carcinoma and cholangiocarcinoma. J Clin Invest. 1996;98: 1313-23.

4. Ince N, de la Monte SM, Wands JR. Overexpression of human aspartyl (asparaginyl) beta-hydroxylase is associated with malignant transformation. Cancer Res. 2000:60:1261-6. 10728685.

5. Aihara A, Huang C-K, Olsen MJ, Lin Q, Chung W, Tang Q, et al. A cell-surface $\beta$-hydroxylase is a biomarker and therapeutic target for hepatocellular carcinoma. Hepatology. 2014;60:1302-13.

6. Sturla L-M, Tong M, Hebda N, Gao J, Thomas J-M, Olsen M, et al. Aspartate$\beta$-hydroxylase (ASPH): a potential therapeutic target in human malignant gliomas. Heliyon. 2016;2:e00203.

7. Nagaoka K, Bai X, Ogawa K, Dong X, Zhang S, Zhou Y, et al. Anti-tumor activity of antibody drug conjugate targeting aspartate- $\beta$-hydroxylase in pancreatic ductal adenocarcinoma. Cancer Lett. 2019;449:87-98.

8. Shimoda M, Tomimaru Y, Charpentier KP, Safran H, Carlson RI, Wands J. Tumor progression-related transmembrane protein aspartate- $\beta$-hydroxylase is a target for immunotherapy of hepatocellular carcinoma. J Hepatol. 2012; 56:1129-35.

9. Tomimaru Y, Mishra S, Safran H, Charpentier KP, Martin W, De Groot AS, et al. Aspartate- $\beta$-hydroxylase induces epitope-specific T cell responses in hepatocellular carcinoma. Vaccine. 2015;33:1256-66.

10. Drakenberg T, Fernlund P, Roepstorff P, Stenflo J. Beta-hydroxyaspartic acid in vitamin K-dependent protein C. Proc Natl Acad Sci U S A. 1983;80:1802-6.

11. Derian CK, VanDusen W, Przysiecki CT, Walsh PN, Berkner KL, Kaufman RJ, et al. Inhibitors of 2-ketoglutarate-dependent dioxygenases block aspartyl beta-hydroxylation of recombinant human factor IX in several mammalian expression systems. J Biol Chem. 1989:264:6615-8. 2708327.

12. Stenflo J, Fernlund P. Beta-hydroxyaspartic acid in vitamin K-dependent plasma proteins from scorbutic and warfarin-treated Guinea pigs. FEBS Lett. 1984;168:287-92

13. Sugo T, Fernlund P, Stenflo J. Erythro-beta-hydroxyaspartic acid in bovine factor IX and factor X. FEBS Lett. 1984;165:102-6.

14. Stenflo J, Lundwall A, Dahlbäck B. Beta-hydroxyasparagine in domains homologous to the epidermal growth factor precursor in vitamin $\mathrm{K}$ dependent protein S. Proc Natl Acad Sci U S A. 1987;84:368-72.

15. Ohlin AK, Landes G, Bourdon P, Oppenheimer C, Wydro R, Stenflo J. Betahydroxyaspartic acid in the first epidermal growth factor-like domain of protein C. its role in Ca2+ binding and biological activity. J Biol Chem. 1988; 263:19240-8. 2461936
16. Stenflo J, Ohlin AK, Owen WG, Schneider WJ. Beta-hydroxyaspartic acid or beta-hydroxyasparagine in bovine low density lipoprotein receptor and in bovine thrombomodulin. J Biol Chem. 1988;263:21-4. 2826439.

17. Persson E, Selander M, Linse S, Drakenberg T, Ohlin AK, Stenflo J. Calcium binding to the isolated beta-hydroxyaspartic acid-containing epidermal growth factor-like domain of bovine factor X. J Biol Chem. 1989;264:16897904. 2789221.

18. Stenflo J, Holme E, Lindstedt S, Chandramouli N, Huang LH, Tam JP, et al. Hydroxylation of aspartic acid in domains homologous to the epidermal growth factor precursor is catalyzed by a 2-oxoglutarate-dependent dioxygenase. Proc Natl Acad Sci U S A. 1989;86:444-7.

19. Gronke RS, VanDusen WJ, Garsky VM, Jacobs JW, Sardana MK, Stern AM, et al. Aspartyl beta-hydroxylase: in vitro hydroxylation of a synthetic peptide based on the structure of the first growth factor-like domain of human factor IX. Proc Natl Acad Sci U S A. 1989:86:3609-13.

20. Korioth F, Gieffers C, Frey J. Cloning and characterization of the human gene encoding aspartyl $\beta$-hydroxylase. Gene. 1994;150:395-9.

21. Feriotto G, Finotti A, Breveglieri G, Treves S, Zorzato F, Gambari R. Multiple

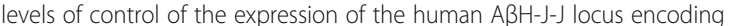
aspartyl- $\beta$-hydroxylase, junctin, and junctate. Ann N Y Acad Sci. 2006;1091: 184-90.

22. Feriotto G, Finotti A, Breveglieri G, Treves S, Zorzato F, Gambari R. Transcriptional activity and Sp 1/3 transcription factor binding to the P1

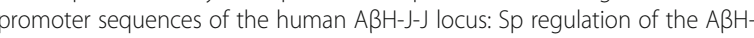
J-J locus P1 promoter. FEBS J. 2007;274:4476-90.

23. Dinchuk JE, Henderson NL, Burn TC, Huber R, Ho SP, Link J, et al. Aspartyl beta -hydroxylase (Asph) and an evolutionarily conserved isoform of Asph missing the catalytic domain share exons with junctin. J Biol Chem. 2000; 275:39543-54

24. Treves S, Feriotto G, Moccagatta L, Gambari R, Zorzato F. Molecular cloning, expression, functional characterization, chromosomal localization, and gene structure of junctate, a novel integral calcium binding protein of sarco(endo)plasmic reticulum membrane. J Biol Chem. 2000;275:39555-68.

25. Lahousse SA, Carter JJ, Xu XJ, Wands JR, de la Monte SM. Differential growth factor regulation of aspartyl-(asparaginyl)- $\beta$-hydroxylase family genes in SH-Sy5y human neuroblastoma cells. BMC Cell Biol. 2006:7:41.

26. Hou G, Xu B, Bi Y, Wu C, Ru B, Sun B, et al. Recent advances in research on aspartate $\beta$-hydroxylase (ASPH) in pancreatic cancer: a brief update. Bosn J Basic Med Sci. 2018;18:297-304.

27. Hong C-S, Kwon S-J, Kim DH. Multiple functions of junctin and junctate, two distinct isoforms of aspartyl beta-hydroxylase. Biochem Biophys Res Commun. 2007:362:1-4.

28. Lee J-H. Overexpression of humbug promotes malignant progression in human gastric cancer cells. Oncol Rep. 2008;19:795-800.

29. Dinchuk JE, Focht RJ, Kelley JA, Henderson NL, Zolotarjova NI, Wynn R, et al. Absence of post-translational aspartyl $\beta$-hydroxylation of epidermal growth factor domains in mice leads to developmental defects and an increased incidence of intestinal neoplasia. J Biol Chem. 2002;277:12970-7.

30. Sepe PS, Lahousse SA, Gemelli B, Chang H, Maeda T, Wands JR, et al. Role of the aspartyl-asparaginyl-beta-hydroxylase gene in neuroblastoma cell motility. Lab Investig. 2002:82:881-91.

31. Jia S, VanDusen WJ, Diehl RE, Kohl NE, Dixon RA, Elliston KO, et al. cDNA cloning and expression of bovine aspartyl (asparaginyl) beta-hydroxylase. J Biol Chem. 1992;267:14322-7. 1378441.

32. Tang $C$, Hou $Y$, Wang $H$, Wang $K$, Xiang $H$, Wan $X$, et al. Aspartate $\beta$ hydroxylase disrupts mitochondrial DNA stability and function in hepatocellular carcinoma. Oncogenesis. 2017;6:e362.

33. Gundogan F, Elwood G, Greco D, Rubin LP, Pinar H, Carlson Rl, et al. Role of aspartyl-(asparaginyl) $\beta$-hydroxylase in placental implantation: relevance to early pregnancy loss. Hum Pathol. 2007;38:50-9.

34. Gundogan F, Bedoya A, Gilligan J, Lau E, Mark P, De Paepe ME, et al. siRNA inhibition of aspartyl-asparaginyl $\beta$-hydroxylase expression impairs cell motility, notch signaling, and fetal growth. Pathol Res Pract. 2011;207:545-53.

35. Palumbo KS, Wands JR, Safran H, King T, Carlson Rl, de la Monte SM. Human aspartyl (asparaginyl) beta-hydroxylase monoclonal antibodies: potential biomarkers for pancreatic carcinoma. Pancreas. 2002;25:39-44.

36. Maeda T, Taguchi K, Aishima S, Shimada M, Hintz D, LaRusso N, et al. Clinicopathological correlates of aspartyl (asparaginyl) $\beta$-hydroxylase overexpression in cholangiocarcinoma. Cancer Detect Prev. 2004;28:313-8.

37. Cantarini MC, de la Monte SM, Pang M, Tong M, D'Errico A, Trevisani F, et al. Aspartyl-asparagyl $\beta$ hydroxylase over-expression in human hepatoma is 
linked to activation of insulin-like growth factor and notch signaling mechanisms. Hepatology. 2006:44:446-57.

38. de la Monte SM, Tamaki S, Cantarini MC, Ince N, Wiedmann M, Carter JJ, et al. Aspartyl-(asparaginyl)- $\beta$-hydroxylase regulates hepatocellular carcinoma invasiveness. J Hepatol. 2006;44:971-83.

39. Yang $H$, Song $K$, Xue T, Xue X-P, Huyan T, Wang W, et al. The distribution and expression profiles of human aspartyl/asparaginyl beta-hydroxylase in tumor cell lines and human tissues. Oncol Rep. 2010;24:1257-64. https://doi. org/10.3892/or_00000980.

40. Wang K, Liu J, Yan Z-L, Li J, Shi L-H, Cong W-M, et al. Overexpression of aspartyl-(asparaginyl)-beta-hydroxylase in hepatocellular carcinoma is associated with worse surgical outcome. Hepatology. 2010;52:164-73.

41. Dong X, Lin Q, Aihara A, Li Y, Huang C-K, Chung W, et al. Aspartate $\beta$ hydroxylase expression promotes a malignant pancreatic cellular phenotype. Oncotarget. 2014;6:1231-48.

42. Lin Q, Chen X, Meng F, Ogawa K, Li M, Song R, et al. ASPH-notch axis guided exosomal delivery of prometastatic secretome renders breast cancer multi-organ metastasis. Mol Cancer. 2019;18:156.

43. Ogawa K, Lin Q, Li L, Bai X, Chen X, Chen H, et al. Aspartate $\beta$-hydroxylase promotes pancreatic ductal adenocarcinoma metastasis through activation of SRC signaling pathway. J Hematol Oncol. 2019;12:144.

44. Maeda T, Sepe P, Lahousse S, Tamaki S, Enjoji M, Wands JR, et al. Antisense oligodeoxynucleotides directed against aspartyl (asparaginyl) $\beta$-hydroxylase suppress migration of cholangiocarcinoma cells. J Hepatol. 2003;38:615-22.

45. Xian Z-H, Zhang S-H, Cong W-M, Yan H-X, Wang K, Wu M-C. Expression of aspartyl beta-hydroxylase and its clinicopathological significance in hepatocellular carcinoma. Mod Pathol. 2006;19:280-6.

46. Luu M, Sabo E, de la Monte SM, Greaves W, Wang J, Tavares R, et al. Prognostic value of aspartyl (asparaginyl)- $\beta$-hydroxylase/humbug expression in non-small cell lung carcinoma. Hum Pathol. 2009;40:639-44.

47. Wang J, de la Monte SM, Sabo E, Kethu S, Tavares R, Branda M, et al. Prognostic value of humbug gene overexpression in stage II colon cancer. Hum Pathol. 2007;38:17-25.

48. Chang WH, Forde D, Lai AG. Dual prognostic role of 2-oxoglutaratedependent oxygenases in ten cancer types: implications for cell cycle regulation and cell adhesion maintenance. Cancer Commun. 2019;39:23.

49. Chen X, Zhao C, Guo B, Zhao Z, Wang H, Fang Z. Systematic profiling of alternative mRNA splicing signature for predicting glioblastoma prognosis. Front Oncol. 2019;9:928.

50. Tomimaru Y, Koga H, Yano H, de la Monte S, Wands JR, Kim M. Upregulation of T-cell factor-4 isoform-responsive target genes in hepatocellular carcinoma. Liver Int. 2013;33:1100-12.

51. Amutha P, Rajkumar T. Role of insulin-like growth factor, insulin-like growth factor receptors, and insulin-like growth factor-binding proteins in ovarian cancer. Indian J Med Paediatr Oncol. 2017;38:198-206. https://doi.org/10. 4103/ijmpo.ijmpo_3_17.

52. Moon RT, Kohn AD, De Ferrari GV, Kaykas A. WNT and beta-catenin signalling: diseases and therapies. Nat Rev Genet. 2004;5:691-701.

53. Bommer GT, Feng Y, lura A, Giordano TJ, Kuick R, Kadikoy H, et al. IRS1 regulation by Wnt/ $\beta$-catenin signaling and varied contribution of IRS1 to the neoplastic phenotype. J Biol Chem. 2010;285:1928-38.

54. Chung W, Kim M, de la Monte S, Longato L, Carlson R, Slagle BL, et al. Activation of signal transduction pathways during hepatic oncogenesis. Cancer Lett. 2016;370:1-9.

55. Kadota M, Sato M, Duncan B, Ooshima A, Yang HH, Diaz-Meyer N, et al. Identification of novel gene amplifications in breast cancer and coexistence of gene amplification with an activating mutation of PIK3CA. Cancer Res. 2009;69:7357-65.

56. Benelli R, Costa D, Mastracci L, Grillo F, Olsen MJ, Barboro P, et al. Aspartate$\beta$-hydroxylase: a promising target to limit the local invasiveness of colorectal cancer. Cancers. 2020;12:971.

57. Yao W-F, Liu J-W, Huang D-S. MiR-200a inhibits cell proliferation and EMT by down-regulating the ASPH expression levels and affecting ERK and PI3K Akt pathways in human hepatoma cells. Am J Transl Res. 2018;10:1117-30. 29736205.

58. Humphries B, Yang C. The microRNA-200 family: small molecules with novel roles in cancer development, progression and therapy. Oncotarget. 2015;6: 6472-98.

59. Chen $X$, Jin $P$, Tang $H$, Zhang L. miR-135a acts as a tumor suppressor by targeting ASPH in endometrial cancer. Int J Clin Exp Pathol. 2019;12:3384-9. 31934181.
60. Carter JJ, Tong M, Silbermann E, Lahousse SA, Ding FF, Longato L, et al. Ethanol impaired neuronal migration is associated with reduced aspartylasparaginyl-beta-hydroxylase expression. Acta Neuropathol. 2008;116:303-15.

61. Borgas DL, Gao J-S, Tong M, Roper N, de la Monte SM. Regulation of aspartyl-(Asparaginyl)- $\beta$-hydroxylase protein expression and function by phosphorylation in hepatocellular carcinoma cells. J Nat Sci. 2015;1:e84. 26 029741.

62. Borgas DL, Gao J-S, Tong M, de la Monte SM. Potential role of phosphorylation as a regulator of aspartyl-(asparaginyl)- $\beta$-hydroxylase: relevance to infiltrative spread of human hepatocellular carcinoma. Liver Cancer. 2015:4:139-53.

63. Tong M, Gao J-S, Borgas D, de la Monte SM. Phosphorylation modulates aspartyl-(asparaginyl)- $\beta$-hydroxylase protein expression, catalytic activity and migration in human immature neuronal cerebellar cells. Cell Biol. 2013;6:133. https://doi.org/10.4172/2324-9293.1000133.

64. Lawton M, Tong M, Gundogan F, Wands JR, de la Monte SM. Aspartyl(asparaginyl) $\beta$-hydroxylase, hypoxia-inducible factor-1a and notch cross-talk in regulating neuronal motility. Oxidative Med Cell Longev. 2010;3:347-56.

65. Brewitz L, Tumber A, Schofield CJ. Kinetic parameters of human aspartate/ asparagine- $\beta$-hydroxylase suggest that it has a possible function in oxygen sensing. J Biol Chem. 2020;295:7826-38.

66. Barboro P, Benelli R, Tosetti F, Costa D, Capaia M, Astigiano S, et al. Aspartate $\beta$-hydroxylase targeting in castration resistant prostate cancer modulates the NOTCH/ HIF1a/GSK3 $\beta$ crosstalk. Carcinogenesis. 2020. https://doi.org/10.1093/carcin/bgaa053.

67. Wang MM. Notch signaling and notch signaling modifiers. Int J Biochem Cell Biol. 2011;43:1550-62.

68. Gridley T. Notch signaling and inherited disease syndromes. Hum Mol Genet. 2003;12:R9-13.

69. Huang Q, Li J, Zheng J, Wei A. The carcinogenic role of the notch signaling pathway in the development of hepatocellular carcinoma. J Cancer. 2019; 10:1570-9.

70. Zou Q, Hou Y, Wang H, Wang K, Xing X, Xia Y, et al. Hydroxylase activity of ASPH promotes hepatocellular carcinoma metastasis through epithelial-tomesenchymal transition pathway. EBioMedicine. 2018;31:287-98.

71. Ogawa K, Lin Q, Li L, Bai X, Chen X, Chen H, et al. Prometastatic secretome trafficking via exosomes initiates pancreatic cancer pulmonary metastasis. Cancer Lett. 2020:481:63-75.

72. Paz H, Pathak N, Yang J. Invading one step at a time: the role of invadopodia in tumor metastasis. Oncogene. 2014;33:4193-202.

73. Iwagami Y, Huang C-K, Olsen MJ, Thomas J-M, Jang G, Kim M, et al. Aspartate $\beta$-hydroxylase modulates cellular senescence through glycogen synthase kinase $3 \beta$ in hepatocellular carcinoma. Hepatology. 2016;63:1213-26.

74. Khan I, Tantray MA, Alam MS, Hamid H. Natural and synthetic bioactive inhibitors of glycogen synthase kinase. Eur J Med Chem. 2017;125:464-77.

75. Huang C-K, Iwagami Y, Zou J, Casulli S, Lu S, Nagaoka K, et al. Aspartate beta-hydroxylase promotes cholangiocarcinoma progression by modulating RB1 phosphorylation. Cancer Lett. 2018;429:1-10.

76. Dunn GP, Bruce AT, Ikeda H, Old LJ, Schreiber RD. Cancer immunoediting: from immunosurveillance to tumor escape. Nat Immunol. 2002;3:991-8.

77. Chang RB, Beatty GL. The interplay between innate and adaptive immunity in cancer shapes the productivity of cancer immunosurveillance. J Leukoc Biol. 2020;108:363-76.

78. Wellenstein MD, de Visser KE. Cancer-cell-intrinsic mechanisms shaping the tumor immune landscape. Immunity. 2018;48:399-416.

79. Huyan $T, L i$ Q, Ye L-J, Yang H, Xue X-P, Zhang M-J, et al. Inhibition of human natural killer cell functional activity by human aspartyl $\beta$ hydroxylase. Int Immunopharmacol. 2014;23:452-9.

80. Palaga T, Buranaruk C, Rengpipat S, Fauq AH, Golde TE, Kaufmann SHE, et al. Notch signaling is activated by TLR stimulation and regulates macrophage functions. Eur J Immunol. 2008:38:174-83.

81. Wang $Y-C$, He F, Feng $F$, Liu X-W, Dong G-Y, Qin $H-Y$, et al. Notch signaling determines the $M 1$ versus $M 2$ polarization of macrophages in antitumor immune responses. Cancer Res. 2010;70:4840-9.

82. Zhao J-L, Huang F, He F, Gao C-C, Liang S-Q, Ma P-F, et al. Forced activation of notch in macrophages represses tumor growth by upregulating miR125a and disabling tumor-associated macrophages. Cancer Res. 2016;76: 1403-15.

83. Amsen D, Helbig C, Backer RA. Notch in T cell differentiation: all things considered. Trends Immunol. 2015;36:802-14. 
84. Kelliher MA, Roderick JE. NOTCH signaling in T-cell-mediated anti-tumor immunity and T-cell-based immunotherapies. Front Immunol. 2018;9:1718.

85. Ayaz F, Osborne BA. Non-canonical notch signaling in cancer and immunity. Front Oncol. 2014:4:345.

86. Janghorban $\mathrm{M}, \mathrm{Xin} \mathrm{L}$, Rosen JM, Zhang XH-F. Notch signaling as a regulator of the tumor immune response: to target or not to target? Front Immunol. 2018;9:1649.

87. Huang C-K, Iwagami Y, Aihara A, Chung W, de la Monte S, Thomas J-M, et al. Anti-tumor effects of second generation $\beta$-hydroxylase inhibitors on cholangiocarcinoma development and progression. PLoS One. 2016;11:e0150336.

88. Nagaoka K, Ogawa K, Ji C, Cao KY, Bai X, Mulla J, et al. Targeting aspartate beta-hydroxylase with the small molecule inhibitor MO--1182 suppresses cholangiocarcinoma metastasis. Dig Dis Sci. 2020. https://doi.org/10.1007/ s10620-020-06330-2.

89. Dahn H, Lawendel JS, Hoegger EF, Fischer R, Schenker E. Über eine neue Herstellung aromatisch substituierter Reduktone. Experientia. 1954:10:245-6.

90. Zheng G, Cox T, Tribbey L, Wang GZ, lacoban P, Booher ME, et al. Synthesis of a FTO inhibitor with anticonvulsant activity. ACS Chem Neurosci. 2014;5: 658-65.

91. Gambacorti-Passerini C, Coutre PL, Piazza R. The role of bosutinib in the treatment of chronic myeloid leukemia. Future Oncol. 2020;16:4395-408.

92. Bailly C. Cepharanthine: an update of its mode of action, pharmacological properties and medical applications. Phytomedicine. 2019;62:152956.

93. Andrews SP, Ball M, Wierschem F, Cleator E, Oliver S, Högenauer K, et al. Total synthesis of five thapsigargins: guaianolide natural products exhibiting sub-nanomolar SERCA inhibition. Chemistry. 2007;13:5688-712.

94. Brewitz L, Tumber A, Thalhammer A, Salah E, Christensen KE, Schofield C Synthesis of novel pyridine-carboxylates as small-molecule inhibitors of human aspartate/asparagine-3-hydroxylase. ChemMedChem. 2020;15:1139-49.

95. Graziano RF, Engelhardt JJ. Role of FcyRs in antibody-based cancer therapy. In: Ravetch JV, Nimmerjahn F, editors. Fc mediated activity of antibodies: structural and functional diversity. Cham: Springer International Publishing; 2019. p. 13-34..

96. Neefjes J, Jongsma MLM, Paul P, Bakke O. Towards a systems understanding of MHC class I and MHC class II antigen presentation. Nat Rev Immunol. 2011;11:823-36.

97. Makkouk A, Weiner GJ. Cancer immunotherapy and breaking immune tolerance: new approaches to an old challenge. Cancer Res. 2015;75:5-10.

98. Noda T, Shimoda M, Ortiz V, Sirica AE, Wands JR. Immunization with aspartate- $\beta$-hydroxylase-loaded dendritic cells produces antitumor effects in a rat model of intrahepatic cholangiocarcinoma. Hepatology. 2012;55:86-97.

99. Iwagami Y, Casulli S, Nagaoka K, Kim M, Carlson Rl, Ogawa K, et al. Lambda phage-based vaccine induces antitumor immunity in hepatocellular carcinoma. Heliyon. 2017;3:e00407.

100. Nordquist LT, Shore ND, Elist JJ, Oliver JC, Gannon W, Shahlaee AH, et al. Phase 1 open-label trial to evaluate the safety and immunogenicity of PAN301-1, a novel nanoparticle therapeutic vaccine, in patients with biochemically relapsed prostate cancer. J Clin Oncol. 2018;36:e15166.

101. Yeung YA, Finney AH, Koyrakh IA, Lebowitz MS, Ghanbari HA, Wands JR, et al. Isolation and characterization of human antibodies targeting human aspartyl (asparaginyl) $\beta$-hydroxylase. Human Antibodies. 2007;16:163-76.

102. Xue T, Xue X-P, Huang Q-S, Wei L, Sun K, Xue T. Monoclonal antibodies against human aspartyl (asparaginyl) beta-hydroxylase developed by DNA immunization. Hybridoma. 2009;28:251-7.

103. Huyan T, Li Q, Dong D-D, Yang H, Xue X-P, Huang Q-S. Development of a novel anti-human aspartyl-(asparaginyl) $\beta$-hydroxylase monoclonal antibody with diagnostic and therapeutic potential. Oncol Lett. 2017;13:1539-46.

104. Revskaya E, Jiang Z, Morgenstern A, Bruchertseifer F, Sesay M, Walker S, et al. A radiolabeled fully human antibody to human aspartyl (asparaginyl) $\beta$-hydroxylase is a promising agent for imaging and therapy of metastatic breast cancer. Cancer Biother Radiopharm. 2017;32:57-65.

105. Yang $H$, Wang $H$, Xue T, Xue X, Huyan T, Wang W, et al. Single-chain variable fragment antibody against human asparty//asparaginyl beta-hydroxylase expressed in recombinant Escherichia coli. Hybridoma. 2011;30:69-79.

106. Pfeffer I, Brewitz L, Krojer T, Jensen SA, Kochan GT, Kershaw NJ, et al. Aspartate/asparagine- $\beta$-hydroxylase crystal structures reveal an unexpected epidermal growth factor-like domain substrate disulfide pattern. Nat Commun. 2019;10:4910.

\section{Publisher's Note}

Springer Nature remains neutral with regard to jurisdictional claims in published maps and institutional affiliations.

Ready to submit your research? Choose BMC and benefit from:

- fast, convenient online submission

- thorough peer review by experienced researchers in your field

- rapid publication on acceptance

- support for research data, including large and complex data types

- gold Open Access which fosters wider collaboration and increased citations

- maximum visibility for your research: over $100 \mathrm{M}$ website views per year

At BMC, research is always in progress.

Learn more biomedcentral.com/submissions 